\title{
A study on nutritional status of the adolescent girls at Khagrachhari district in Chittagong hill tracts, Bangladesh
}

\author{
G. M. Mosarrof Hossain ${ }^{1}$, Md. Tanvir Sarwar, ${ }^{1,}$, M. Hafizur Rahman ${ }^{1}$, Shakh M. A. Rouf ${ }^{1}$, \\ Salim Raza ${ }^{1}$, Asad Ud- Daula ${ }^{1}$, Sabir Hossain ${ }^{2}$ \\ ${ }^{1}$ Department of Applied Nutrition and Food Technology, Islamic University, Kushtia, Bangladesh \\ ${ }^{2}$ Department of Biochemistry and Molecular Biology, Jahangirnagar University, Savar, Dhaka, Bangladesh
}

Email address:

tanvirsarwariu@gmail.com (Md. T. Sarwar)

\section{To cite this article:}

G. M. Mosarrof Hossain, Md. Tanvir Sarwar, M. Hafizur Rahman, Shakh M. A. Rouf, Salim Raza, Asad Ud- Daula, Sabir Hossain. A Study on Nutritional Status of the Adolescent Girls at Khagrachhari District in Chittagong Hill Tracts, Bangladesh. American Journal of Life Sciences. Vol. 1, No. 6, 2013, pp. 278-282. doi: 10.11648/j.ajls.20130106.17

\begin{abstract}
This study deals with the nutritional profile of adolescent girls on the basis of data collected from sample survey of 300 respondents from Khagrachhari district in Chittagong hill tracts region of Bangladesh by cross sectional method. This study found that about $66.00 \%$ of adolescent girls lived in rural and only $34.00 \%$ lived in urban area of Khagrachhari district. About $93.00 \%$ of adolescent girls were tribes and only $7.00 \%$ were Bengali. According to the BMI level $41.33 \%$ of adolescent girls were underweight, $35.00 \%$ normal, $8.33 \%$ overweight and $6.67 \%$ obese. Their nutritional status were very poor because $65 \%$ adolescent girls intake low food, $15.67 \%$ undergo married during adolescent period. Among the adolescent girls the percentage of non school going was 11.60 and above class eight were only 21.67 . The light spark of this study is $28.34 \%$ of the adolescent girl's intake diet more than the normal ( $1900 \mathrm{kcal}$. per day), $63.40 \%$ maintains hygienity. Study also shows that nutritional awareness developed $43.33 \%$ through mass media such as Television, Radio and Newspaper. Friends and family members also play a vital role to improve their nutritional awareness.
\end{abstract}

Keywords: Adolescent Girls, Underweight, Malnutrition, Nutritional Status

\section{Introduction}

The World Health Organization (WHO) ${ }^{1}$ defines adolescents as young people aged 10-19 years. There are about 1.2 billion adolescents, a fifth of the world's population, and their numbers are increasing. Four out of five live in developing countries. Many boys and girls in developing countries enter adolescence undernourished, making them more vulnerable to disease and early death. Conversely, overweight and obesity - another form of malnutrition with serious health consequences - is increasing among other young people in both low and high income countries. Adequate nutrition and healthy eating and physical exercise habits at this age are foundations for good health in adulthood ${ }^{2}$. Adolescents are the best human resources. But for many years, their health has been neglected because they were considered to be less vulnerable to disease than the young children or the very old. Their health attracted global attention in the last decade only $^{3}$. As adolescents have a low prevalence of infection compared with under-five children, and of chronic disease compared with ageing people, they have generally been given little health and nutrition attention, except for reproductive health concerns ${ }^{4}$.

Between 10 and 19 years of age, the requirement for many micronutrients, including vitamin $\mathrm{A}$, thiamine, riboflavin, niacin, folic acid, vitamin $\mathrm{B} 12$, vitamin $\mathrm{C}$, and iodine, reaches levels required by pregnant women. Moreover, rapid growth produces a higher requirement among adolescents 10-14 years of age for calcium than any other population age group except pregnant women. The 2,420 kcal required per day by adolescents 15-19 years of age are the highest energy requirement of any age group. The recommended general daily dietary allowances of $2100 \mathrm{kcal} /$ person/day for populations wholly dependent on food is based on a distribution of age and sex which assumes that $20 \%$ of the population are adolescents $10-19$ years of age and $56 \%$ are adults. In populations with a higher proportion of adolescents or adults, this food may provide insufficient energy $^{5}$. Adolescence may also present a nutritional 
opportunity, although little is known about the short and long-term effects of acute under nutrition during adolescence. In many cultures, a large proportion of girls have their first pregnancy during adolescence. Improvement in nutritional status can improve pregnancy outcomes, including maternal death, fetal death, and preterm delivery, experienced by pregnant adolescents ${ }^{6}$.

Malnourished adolescent girls who have babies at a young age are more likely to experience, and will be less able to withstand, complications because the body has not yet reached maturity. Maternal mortality is higher in anemic women. Even when they survive, poorly nourished adolescent mothers are more likely to give birth to low birth-weight babies, perpetuating a cycle of health problems which pass from one generation to the next. Hence it is essential to assess the nutritional status of adolescence girls, especially developing countries like Bangladesh.

\section{Methodology}

Among several types of study design a cross sectional study was conducted. A total of 300 adolescent girls were randomly selected from rural and urban areas of Khagrachhari District in Chittagong Hill Tracts region of Bangladesh. A detailed physical examination and dietary history was done and the various infections or infestations associated with malnutrition were evaluated by detail history, clinical examination. The survey form was prepared in two sections. The first part was conducted in order to assess the nutritional status by taking anthropometric measurement and dietary history of the adolescent girls and the second part was prepared for examining presence of any disease.

Sample size was estimated by following equation-

$$
n=\frac{(1.96)^{2} \times(1-p)}{P \times \varepsilon^{2}}
$$

Where:

$\mathrm{n}=$ sample size required

$\mathrm{p}=$ expected prevalence of disorder in the population, as the prevalence of disorder is not known before the survey is done, as estimate must be used this usually an experienced guess or derived from a small pilot survey.

$\varepsilon=$ relative precision required 1.96 is a statistical parameter corresponding to the confidence level of $95 \%$ (An error risk of 5\%)

$\mathrm{p}$ and e can be expressed either as percentage or as fractions $(10 \%=0.10)$ but must both be expressed in the same terms.

The Study Instrument was questionnaire and some standard technique of anthropometric Measurements ${ }^{7}$.

A questionnaire was developed to obtain relevant information on anthropometric data, dietary information, health information, socio-economic condition. Information on date of birth, monthly family income, parent's educational status, possession of expensive household articles, immunization coverage, nutrition knowledge, etc. was collected using a structured questionnaire. Height and weight were measured using standard techniques. 24-hour recall method was used for obtaining data on nutrient intakes. Nutritional status was determined by anthropometric measurement performing standard methods (NCHS), Gomez Classification, Water Low classification and Z-score measurement.

\section{Results}

After surveying on 300 adolescent girls in the district of Khagrachhari in Chittagong hill tracts region of Bangladesh \& comparing various data we obtain the following result.

Table 1. Distribution of adolescent girls by age group

\begin{tabular}{ccc}
\hline Age in year & Adolescent girls & \% Adolescent girls \\
\hline $11--13$ & 91 & 30.33 \\
$14--16$ & 124 & 41.33 \\
$17--19$ & 85 & 28.34 \\
\hline
\end{tabular}

Table-1 shows the distribution of adolescent girls according to age group $30.33 \%$ of adolescent girls belonged to $11-13$ years. $41.33 \%$ of adolescent girls were in the age group 14-16 years. $28.34 \%$ of adolescent girls were belonged to age group 17-19 years. Majority of the adolescent girls at Khagrachhari District in Chittagong hill tracts region of Bangladesh were in 14-16 years.

Table 2. Distribution of adolescent girls by area (Urban/Rural)

\begin{tabular}{ccc}
\hline Area & Adolescent girls & \% of Adolescent girls \\
\hline Rural & 196 & 66 \\
Urban & 104 & 34 \\
\hline
\end{tabular}

Table 2 shows the distribution of adolescent girls according to area at Khagrachhari District in Chittagong hill tracts region of Bangladesh about $66 \%$ of adolescent girls were rural area while only $34 \%$ of adolescent girls were urban area. Majority of adolescent girls were rural area.

Table 3. Distribution of adolescent girls by education level

\begin{tabular}{lcc}
\hline Level of education & Adolescent girls & \% of adolescent girls \\
\hline Non School going & 35 & 11.6 \\
Less than class six & 90 & 30 \\
Class six to Eight & 110 & 36.67 \\
Class Eight to S.S.C & 65 & 21.67 \\
\hline
\end{tabular}

Table 3 shows the distribution of adolescent girls according to education level. $11.6 \%$ of adolescent girls were non educated, $30 \%$ of adolescent girls $<$ class six, $36.67 \%$ of adolescent girls were class six $t$ to eight ,21.67\% of adolescent girls were class eight to S.S.C at Khagrachhari District in Chittagong hill tracts region of Bangladesh. 
Table 4. Distribution of adolescent girls by their marital status

\begin{tabular}{ccc}
\hline $\begin{array}{c}\text { Total number of } \\
\text { adolescent girl }\end{array}$ & $\begin{array}{c}\text { Number of } \\
\text { unmarried } \\
\text { adolescent girl }\end{array}$ & $\begin{array}{c}\text { Number of married } \\
\text { adolescent girl }\end{array}$ \\
\hline 300 & $253(84.33 \%)$ & $47(15.67 \%)$ \\
\hline
\end{tabular}

Table-4 shows those $84.33 \%$ adolescent girls are unmarried and $15.67 \%$ are married in the present study at Khagrachhari District in Chittagong hill tracts region of Bangladesh.

Table 5. Distribution of adolescent girls by environmental status

\begin{tabular}{ccc}
\hline Hygienic level & Adolescent girls & \% of adolescent girls \\
\hline Hygienic & 190 & 63.4 \\
Unhygienic & 110 & 36.6 \\
\hline
\end{tabular}

Table 5 shows the distribution of adolescent girls according to their living status at Khagrachhari District in Chittagong hill tracts region of Bangladesh $63.40 \%$ of adolescent girls maintain hygienity and $36.6 \%$ unhygienic.

Table 6. Distribution of adolescent girls by level of food intake

\begin{tabular}{ccc}
\hline $\begin{array}{c}\text { Level of food } \\
\text { consumption }\end{array}$ & Adolescent girls & \% of adolescent girls \\
\hline Normal (1600-1900) & 120 & 40.00 \\
Above normal & 85 & 28.34 \\
Less than normal & 95 & 31.66 \\
\hline
\end{tabular}

Table 6 shows the distribution of adolescent girls according to level of food consumption at Khagrachhari District in Chittagong hill tracts region of Bangladesh about $40 \%$ of adolescent girls take normal, and $28.34 \%$ take more than normal and $31.66 \%$ of adolescent girls take less than normal respectively.

Table 7. Distribution of adolescent girls by awareness about the complication of low food intake

\begin{tabular}{ccc}
\hline Awareness & No of Adolescence girls & \% of Adolescence girls \\
\hline Yes & 195 & 65 \\
No & 105 & 35 \\
\hline
\end{tabular}

Table 7 shows the distribution of adolescent girls by concept about low food intake at Khagrachhari District in Chittagong hill tracts region of Bangladesh about $65 \%$ of adolescence girls have awareness about low food intake and $35 \%$ are not aware about low food intake.

Table 8. Distribution of adolescent girl's awareness developed by

\begin{tabular}{lcc}
\hline \multicolumn{1}{c}{ Awareness } & $\begin{array}{c}\text { No of adolescent } \\
\text { girls }\end{array}$ & $\begin{array}{c}\text { \% of adolescent } \\
\text { girls }\end{array}$ \\
\hline Nutritionist/Physician & 30 & 10.00 \\
Family members & 95 & 31.67 \\
Friends & 45 & 15.00 \\
$\begin{array}{l}\text { Mass media(TV/Radio/News } \\
\text { paper) }\end{array}$ & 130 & 43.33 \\
\hline
\end{tabular}

Table 8 shows the distribution of adolescent girls' how awareness developed. Adolescent girls aware by nutritionist/physician $31.67 \%$, aware by family members $15.00 \%$, by their friends \& major of $43.33 \%$ of adolescence girls aware by mass media such as TV, Radio and News paper etc.

Table 9. Distribution of adolescent girls having food taboos

\begin{tabular}{ccc}
\hline Food taboos & Adolescent girls & \% of adolescent girls \\
\hline Yes & 275 & 91.66 \\
No & 25 & 8.34 \\
\hline
\end{tabular}

Table 9 shows the distribution of adolescent girls by food taboos at Khagrachhari District in Chittagong hill tracts region of Bangladesh $91.66 \%$ of adolescent having food taboos and $8.34 \%$ not believe food taboos.

Table 10. Distribution of adolescent girl's nutritional status according to BMI classification

\begin{tabular}{ccc}
\hline $\begin{array}{c}\text { BMI category } \\
\left(\mathbf{~ k g} / \mathbf{m}^{2}\right)\end{array}$ & Weight category & No of adolescent girl (\%) \\
\hline Less than 18.5 & Underweight & $150(50 \%)$ \\
$18.5-24.9$ & Normal & $105(35 \%)$ \\
$25-29.9$ & Overweight & $25(8.33 \%)$ \\
Above 30 & Obese & $20(6.67 \%)$ \\
\hline
\end{tabular}

Table 10 shows that $50 \%$ adolescent girls are underweight, $35 \%$ are normal, $8.33 \%$ are overweight and $6.67 \%$ are obese according to the BMI level at Khagrachhari District in Chittagong hill tracts region of Bangladesh.

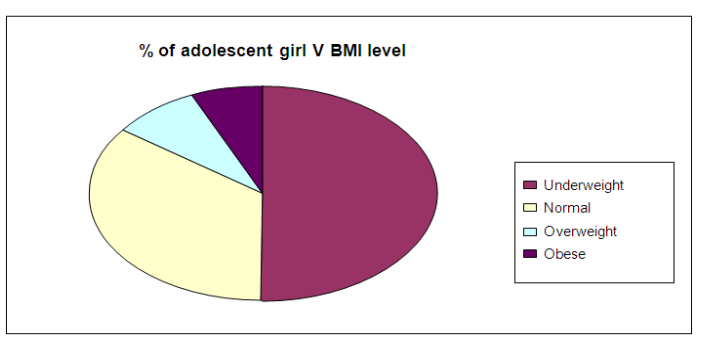

Fig 1. Percent distribution of adolescent girls according to BMI classification at Khagrachhari District in Chittagong hill tracts region of Bangladesh.

According to Gomez Classification $14.33 \%$ of adolescent girls were normal, $36.67 \%$ of adolescent girls were mild-malnourished, $18 \%$ were moderately-malnourished and $14.67 \%$ were severely-malnourished.

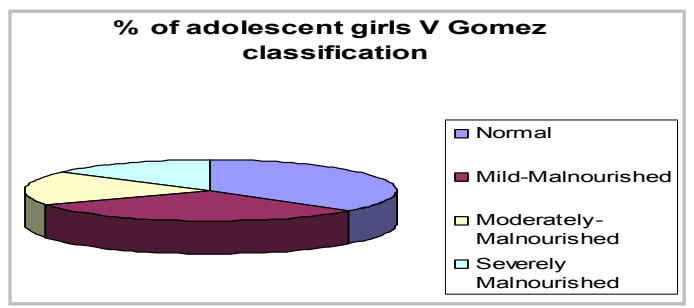

Fig 2. Percent distribution of adolescent girls according to Gomez Classification (Weight for age). 
According to Water Low Classification Height-for-age \& Weight-for-height) distribution of Adolescent girls at Khagrachhari District in Chittagong hill tracts region of Bangladesh about $36 \%$ adolescent girls were normal, $33.34 \%$ were stunted, $26.6 \%$ were wasted and $4 \%$ were both stunted and wasted.

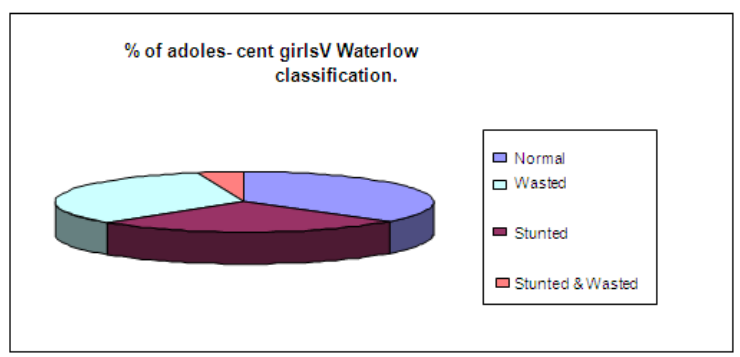

Fig 3. Percentage distribution of adolescent girls according to Water low Classification (Height for age \& Weight for eight) at Khagrachhari District in Chittagong hill tracts region of Bangladesh.

The growth performance of the adolescent girls using the indicator-weight for age (W/A Z score) at Khagrachhari District in Chittagong hill tracts region of Bangladesh.7\% of the adolescent girls are severely underweight (-3SD) $25 \%$ are moderately underweight (-2.00 - to $-2.99 \mathrm{SD}), 30.67 \%$ adolescent girls are mildly underweight (-1.99 to $-1.00 \mathrm{SD})$ and $37.33 \%$ are normal ( $-0.99 \mathrm{SD}$ to $+0.99 \mathrm{SD})$.

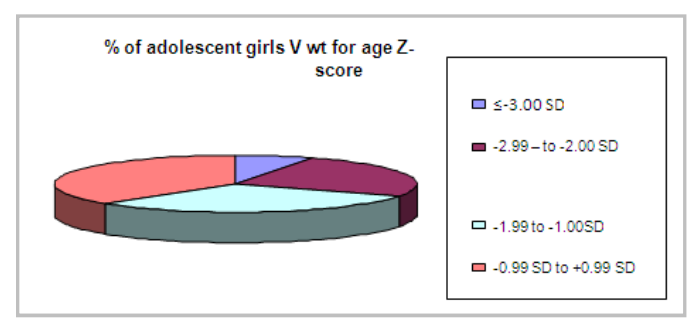

Fig 4. Percentage distribution of adolescent girl's nutritional status by weight for age according to Z-score.

The growth performance of the adolescent girls using the indicator-weight for height according to the $\mathrm{Z}$-score at Khagrachhari District in Chittagong hill tracts region of Bangladesh.12\% of the adolescent girls were severely wasted ( $-3.00 \mathrm{SD}), 27 \%$ were moderately wasted $(-2.99-$ to -2.00 SD), $21.67 \%$ adolescent girls were mildly wasted ( -1.99 to $-1.00 \mathrm{SD})$ and $37.33 \%$ is normal $(-0.99 \mathrm{SD}$ to +0.99 $\mathrm{SD})$.

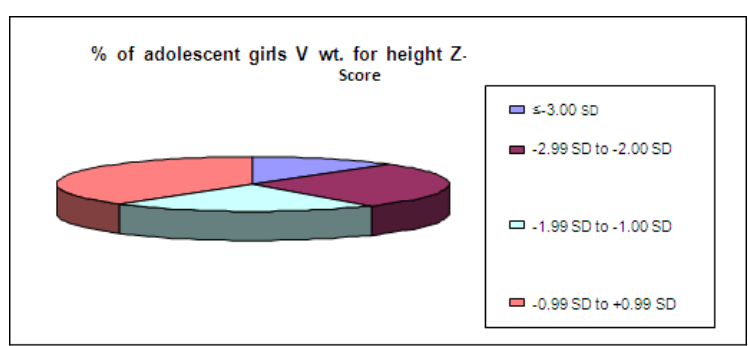

Fig 5. Percentage distribution of adolescent girl's nutritional status by weight for height according to Z-score at Khagrachhari District in Chittagong hill tracts region of Bangladesh.
The growth performance of the adolescent girls using the indicator height for age according to the $\mathrm{Z}$-score at Khagrachhari District in Chittagong hill tracts region of Bangladesh.13.67\% of the adolescent girls are severely stunted (-3SD), $20.33 \%$ are moderately stunted (-2.00 - to $-2.99 \mathrm{SD}), 28 \%$ adolescent girls are mildly stunted (-1.99 to $-1.00 \mathrm{SD})$ and $38 \%$ is normal (-0.99 SD to $+0.99 \mathrm{SD})$.

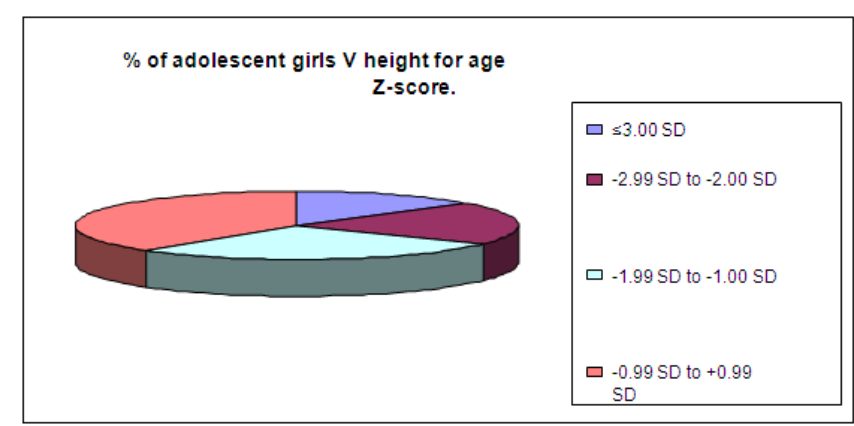

Fig 6. Percentage distribution of adolescent girl's nutritional status by height for age according to Z-score at Khagrachhari District in Chittagong hill tracts region of Bangladesh.

\section{Discussion}

Adolescence, a period of transition between childhood and adulthood, occupies a crucial position in the life of human beings. This period is characterized by an exceptionally rapid rate of growth. The peak rates of growth are exceeded only during the fetal life and early infancy $^{8}$.The poor nutritional status of adolescents, especially girls, has important implications in terms of physical work capacity and adverse reproductive outcomes ${ }^{9}$. Adolescents (aged 10 to 19 years) have specific health and development needs, and many face challenges that hinder their well being. The findings of this study are kind of similar to some of the previous studies ${ }^{10}$. This is a prospective study performed in urban \& rural areas to find out the determinants the nutritional status of adolescent girls of at Khagrachhari District in Chittagong hill tracts region of Bangladesh. The factors influencing nutritional status of adolescent girls are age, weight, height, anemic status, vaccination, educational qualification of parents, family income, family size, living status etc. Many factors of risks of malnutrition are present in the surveyed area. Sanitation conditions are very poor and responsible of hygiene related diseases like worms infections that can conduct to malnutrition.

This study found that about $66.00 \%$ of adolescent girls lived in rural and only $34.00 \%$ lived in urban. About $93.00 \%$ of adolescent girls were Tribes and only $7.00 \%$ Bengali. Their nutritional status were very poor because $65 \%$ adolescent girls intake low food, $15.67 \%$ undergo married during adolescent period. Level of education has a significant independent effect on nutritional status in adolescent girls. Present study showed that, a tendency towards an increase nutritional status in adolescent girls with an increase in the level of their education. About $11.6 \%$ of 
adolescent girls were non educated, $30 \%$ of adolescent girls $<$ class six, $36.67 \%$ of adolescent girls were class six $t$ to eight, $21.67 \%$ of adolescent girls were class eight to S.S.C at Khagrachhari District in Chittagong hill tracts region of Bangladesh. This may due to the relatively better understanding of public health knowledge in public health \& nutritional status of adolescent girls. Parent's educational level also influences nutritional status of adolescent girls. Makheja et al strongly suggests that the parent's educational status is a very important significant determinant of birth weight. Better understanding of health care awareness of nutritional status \& mental, nutritional support to adolescent girls may be related to good nutritional status.

Family monthly income is another determinant of nutritional status of adolescent girls. The distribution of adolescent girls according to monthly family income at Khagrachhari in Chittagong hill tracts region of Bangladesh. About $30.00 \%$ of adolescent girls were family income $<3000.38 .34 \%$ of adolescent girls were family income $3000-4000$. And $20.00 \%$ of adolescent girls were family income $4000-6000.11 .66 \%$ of adolescent girls were family income $>6000$. Majority of Adolescent girl's monthly family income were $3000-4000$ which are also affect nutritional status in adolescent girls. Present study observed that a tendency towards an increase nutritional status in adolescent girls with an increase in the family income. This may due to the relatively better understanding of the public health knowledge in public health \& nutritional status of adolescent girls. Family size also influences nutritional status of adolescent girls. After surveying it has been found that maximum $10.33 \%$ of adolescent girls were family size 2 . $21.33 \%$ of adolescent girls were family size $3.36 .53 \%$ of adolescent girls were family size 4 . Majority of family size up to 4 . Present study showed that, when increase in family size, decrease in nutritional status in adolescent girls.

Living status is another indicator of nutritional status. Shows the distribution of adolescent girls according to Gomez Classification (wt-for-age) at Khagrachhari in Chittagong hill tracts region of Bangladesh about $14.33 \%$ of adolescent girls were Normal.36.67\% of adolescent girls were $\quad$ Mild-malnourished, $\quad 18 \% \quad$ were Moderately-malnourished, and about $14.67 \%$ were severely-malnourished. According to Water low classification (Height-for-age \& Weight-for-height) about $36 \%$ adolescent girls were normal, $33.34 \%$ were stunted, $26.6 \%$ were wasted and $4 \%$ were both stunted and wasted. According to the BMI level $41.33 \%$ of adolescent girls were underweight, $35.00 \%$ normal, $8.33 \%$ overweight and $6.67 \%$ obese. Majority of the adolescent girls were in 14-16 years of age and their family size were up to $4.66 .66 \%$ of their father's occupation is agriculture and monthly income is under the extreme range of poverty. $91.66 \%$ of adolescent girl's having food taboos and about 94\% suffer severe infectious disease like malaria, diarrhea, anemia etc. The nutritional status and energy intake of adolescents at
Khagrachari in Chittagong hill tracts region of Bangladesh is poor. The light spark of this study is $28.34 \%$ of adolescent girl's intake diet more than the normal (1900 kcal.per day), $63.40 \%$ maintains hygienity. Study also shows that nutritional awareness developed $43.33 \%$ through mass media such as Television, Radio, and Newspaper. Friends and family members also play a vital role.

The low values for anthropometry and socio-economic level obtained from this study suggest that there is need for improvement in the nutritional status of these adolescents. Also, more attention needs to be done to address the issue of adolescent malnutrition. Various macro and micro- nutrient deficiencies are more common nutritional problems in Bangladesh. This may arise different types of complications that may be life threaten for adolescent girls. There is no magic pill that can reduce or increase the nutritional status of the girls. If the individuals are conscious about nutritional knowledge, nutritional deficiency diseases, nutritional value of food and dietary practices, they can easily overcome those problems and can make sound health and body without wasting excess money.

\section{References}

[1] World Health Organization. Adolescent Friendly Health Services, 2002, An agenda for change, Geneva, WHO Publications, $5-9$

[2] http://www.who.int/features/factfiles/adolescen t_health/en/ Accessed on 10.08.2011.

[3] Kalhan M, Vashisht B, Kumar V, Sharma S, 2010, Nutritional status of adolescent girls of rural Haryana. Internet J Epidemiol 8(1).

[4] Senderowitz J, 1995, Adolescent health: reassessing the passage to adulthood. World Bank Discussion Paper No. 272, Washington, D.C: World Bank.

[5] WHO, 2000. The management of nutrition in major emergencies World Health Organization, Geneva.

[6] ACC/SCN, 2000. Fourth Report on the World Nutrition Situation. ACC/SCN, Geneva.

[7] Derrick B Jelliffe, 1989, Direct assessment of Nutritional status, Community Nutritional assessment, Oxford University Press, 13-30.

[8] Tanner JM, 1978, Fetus into Man: Physical Growth from Conception to Maturity. Wells, Open Book Publishing Limited.

[9] Haboubi J, Rizwana B, A, 2009; Comparision of the Nutritional status of adolescents from the selected schools of south India and UAE: A Cross-sectional study. Indian J Com Med 34(2):108-111.

[10] Yogesh Saxena, Vartika Saxena, 2011 July, Nutritional Status in Rural Adolescent Girls Residing at Hills of Garhwal in India, Internet Journal of Medical Update;6(2):3-8. 